\title{
Kepuasan Pemustaka Terhadap Kegiatan Sosialisasi Layanan di UIN Sunan Gunung Djati Bandung
}

\author{
Eded Sudirman', L. Nailah Hanum Hanany ${ }^{2}$, Robi' in ${ }^{3}$ \\ Pusat Perpustakaan UIN Sunan Gunung Djati Bandung \\ Email: ${ }^{1}$ eded.sudirman@uinsgd.ac.id, ${ }^{2}$ nailah.hanany@uinsgd.ac.id, \\ ${ }^{3}$ robiin@uinsgd.ac.id
}

\begin{abstract}
One of the activities to attract the interest of library users, need to use the service marketing triangle which includes internal marketing, external marketing and interactive marketing. Currently, the UIN Sunan Gunung Djati Library Center is conducting socialization as part of an external marketing effort to attract service users. In terms of service dissemination activities to new students, the main target is the increased utilization of library services by students. So far there has been no measure of whether this outreach activity really reaches its goals or not. In addition, information must also be obtained from users, especially new students about what are their needs and expectations so that their interest in utilizing library services is getting higher. Research is carried out by survey methods for new students who have received service socialization. The respondents were 282 people determined by the Slovin method. Based on the results of the research, it can be concluded that socialization activities have a positive effect on the level of access of users to library services. In terms of satisfaction with socialization activities, more than $70 \%$ of respondents were satisfied and the information submitted was adequate, but respondents felt the facilities used still needed to be improved, especially the availability of internet access.
\end{abstract}

\section{Abstrak}

Salah satu kegiatan untuk menarik minat pengguna perpustakaan, perlu menggunakan segitiga pemasaran jasa yang meliputi pemasaran internal, pemasaran eksternal 
dan pemasaran interaktif. Saat ini, Pusat Perpustakaan UIN Sunan Gunung Djati sedang melakukan sosialisasi sebagi bagian dari upaya pemasaran eksternal untuk menarik minat pengguna layanan. Dalam hal kegiatan sosialisasi layanan kepada mahasiswa baru, sasaran utamanya adalah meningkatnya pemanfaatan layanan perpustakaan oleh mahasiswa. Sejauh ini belum ada ukuran apakah kegiatan sosialisasi ini benar-benar mencapai sasarannya atau tidak. Selain itu, perlu juga diperoleh informasi dari pengguna, khususnya mahasiswa baru mengenai hal apa saja yang menjadi kebutuhan dan harapan mereka agar minat mereka memanfaatkan layanan perpustakaan semakin tinggi

Riset dilakukan dengan metode survey terhadap mahasiswa baru yang sudah mendapatkan sosialisasi layanan. Responden berjumlah 282 orang ditentukan dengan metode Slovin. Berdasarkan hasil riset, dapat disimpulkan bahwa kegiatan sosialisasi berpengaruh positif terhadap tingkat akses pemustaka terhadap layanan perpustakaan. Dalam hal kepuasan terhadap kegiatan sosialisasi, lebih dari 70\% responden merasa puas dan informasi yang disampaikan memadai, tetapi responden merasa sarana yang digunakan masih perlu ditingkatkan, terutama ketersediaan akses internet.

Kata Kunci: kepuasan, sosialisasi layanan, pemanfaatan layanan, survey

\section{Pendahuluan}

Perpustakaan merupakan institusi yang bersifat ilmiah, sehingga semua kegiatan didalamnya mengandung suatu nilai dan unsur pembelajaran, penelitian, pembinaan, pengembangan, ilmu pengetahuan, dan lainlain yang berorientasi pada pencerahan dan penambahan wawasan bagi penggunanya. Sebagai penyimpan khazanah budaya bangsa perpustakaan berusaha meningkatkan apresiasi dan minat kunjung pemustaka melalui proses penyediaan bahan bacaan (Suwarno, 2009).

Perpustakaan merupakan salah satu media untuk memenuhi kebutuhan informasi (Yusuf, 2001). Perpustakaan mengelola informasi yang dibutuhkan pemustaka secara mudah, cepat, dan tepat (K \& Octavia, 2001). Karena setiap pemustaka memiliki kebutuhan dan harapan yang berbeda-beda maka perpustakaan selalu berupaya untuk mengerti kebutuhan dan harapan pemustaka (K O. I., 2003). Kegiatan perpustakaan yang langsung dirasakan oleh pemakai adalah pelayanan, karena pelayanan dianggap ujung tombak 
perpustakaan (Soeatminah, 1992).Banyak jenis pelayanan yang disediakan perpustakaan, yang berjumlah tidak kurang dari 17 layanan termasuk layanan sirkulasi dan layanan penelusuran informasi/literatur(Akbar). Dalam rangka menarik minat pengguna untuk memanfaatkan berbagai layanan, sudah banyak dilakukan oleh Perpustakaan di setiap sekolah/Perguruan Tinggi. Upaya tersebut misalnya dengan menambah koleksi, mengadakan pameran buku, menata ruangan, mengadakan perlombaan seperti lomba karya tulis dan sosialisasi (Rangkuti, 2016). Selain itu, untuk menarik minat pengguna perpustakaan, perlu menggunakan segitiga pemasaran jasa yang meliputi pemasaran internal, pemasaran eksternal dan pemasaran interaktif (Az’mi, 2013). Saat ini, Pusat Perpustakaan UIN Sunan Gunung Djati sedang melakukan sosialisasi sebagi bagian dari upaya pemasaran eksternal untuk menarik minat pengguna layanan.

Dikaitkan dengan efisiensi kegiatan perpustakaan, perlu diperhatikan apakah suatu kegiatan berdampak pada ketercapaian outputnya atau tidak. Dalam hal kegiatan sosialisasi layanan kepada mahasiswa baru, sasaran utamanya adalah meningkatnya pemanfaatan layanan perpustakaan oleh mahasiswa. Sejauh ini belum ada ukuran apakah kegiatan sosialisasi ini benar-benar mencapai sasarannya atau tidak. Selain itu, perlu juga diperoleh informasi dari pengguna, khususnya mahasiswa baru mengenai hal apa saja yang menjadi kebutuhan dan harapan mereka agar minat mereka memanfaatkan layanan perpustakaan semakin tinggi.

\section{Metode Penelitian}

\section{Jenis Penelitian}

Penelitian ini merupakan jenis penelitian deskriptif melalui metode survey. Sementara berdasarkan jenis datanya, penelitian ini merupakan penelitian kuantitatif, prosedur penelitian yang menggunakan angka dalam penyajian dan analisis yang menggunakan uji statistika, penelitian kuantitatif merupakan penelitian yang dipandu oleh hipotesis tertentu yang salah satu tujuannya dari penelitian yang dilakukan adalah menguji hipotesis yang 
ditentukan sebelumnya(Saebani, 2008). Data yang diolah pada penelitian ini merupakan data kuantitatif.

\section{Data dan Sumber Data}

Berdasarkan sumbernya, data yang digunakan dalam penelitian ini terdiri dari dua macam, yaitu:

1. Data sekunder, data yang diperoleh dari hasil kajian literatur, seperti data jumlah populasi.

2. Data primer, data yang diperoleh dari hasil survey dengan kuisioner untuk melihat pengaruh sosialisasi terhadap tingkat pemanfaatan layanan perpustakaan.

\section{Teknik Pengambilan Data}

Metode pengumpulan data yang digunakan adalah kuesioner dan wawancara. Populasi dalam penelitian ini adalah seluruh mahasiswa UIN. Jumlah sampel ditentukan dengan persamaan Slovin(Setiawan, 2007):

$$
n=\frac{\mathrm{N}}{1+\mathrm{n}\left(\mathrm{d}^{3}\right)}
$$

Dimana:

$\mathrm{n}=$ Jumlah sampel

$\mathrm{N}=$ Jumlah populasi

$\mathrm{d}=$ tingkat kepercayaan/ketepatan yang diinginkan

Pada penelitian ini, jumlah populasi merupakan jumlah mahasiswa yang sudah mengikuti sosialisasi layanan perpustakaan dengan jumlah 960 orang. Dengan tingkat kesalahan sebesar 5\%, menggunakan metode Solvin, di dapat jumlah responden sebanyak 282 orang. Pemilihan responden dilakukan dengan menggunakan teknik purposive, dimana responden yang diwawancara adalah responden yang pernah mengikuti sosialisasi layanan. 


\section{Variabel dan kerangka pikir}

Diagram di bawah ini menunjukan variabel dan kerangka pikir penelitian yang menjadi fokus utama dalam penelitian.

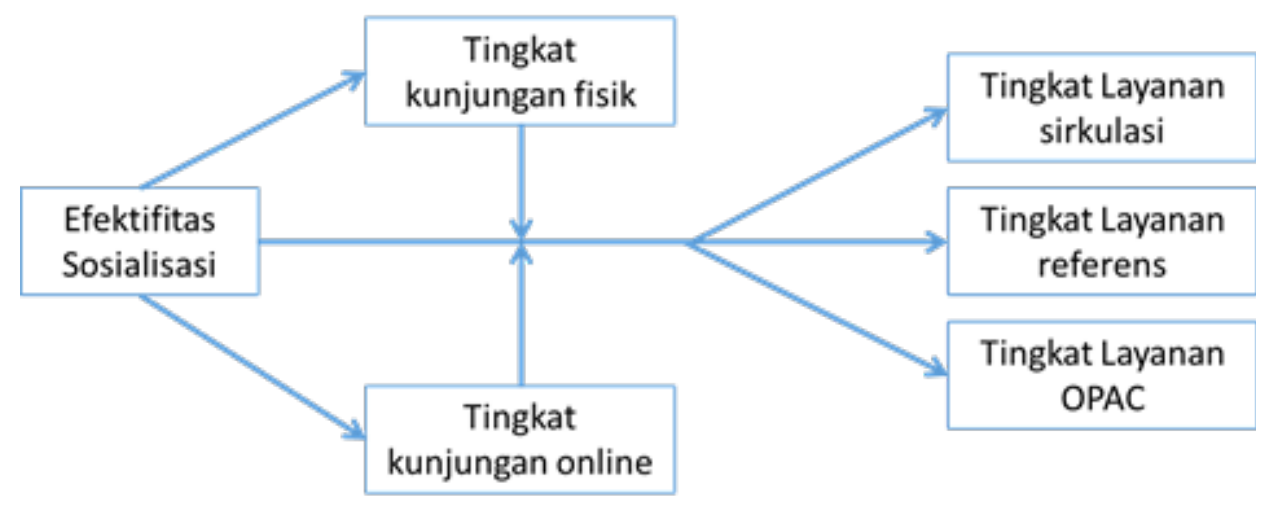

Gambar 1. Variabel dan kerangka pikir

Efektifitas sosialisasi akan ditinjau dari 2 sisi, yaitu: tingkat kunjungan fisik dan tingkat konjungan online.

\section{Hasil dan Pembahasan}

\section{Kepuasan Responden Terhadap Kegiatan Sosialisasi}

Berdasarkan hasil survey, dapat dilihat bahwa secara umum responden yang merasa puas terhadap kegiatan sosialisasi Pustakawan di atas $50 \%$. Dalam pengelolaan ini, yang termasuk Puas adalah responden yang memilih PUAS (4) dan SANGAT PUAS (5). Sementara yang tidak puas adalah responden yang memilih TIDAK PUAS (2) dan SANGAT TIDAK PUAS (3). Kalau dilihat per atribut pertanyaan, kepuasaan ini bervariasi. Responden paling banyak merasa puas untuk atribut No. 1, "Informasi yang disampaikan cukup memadai", yaitu 73,4\%, artinya ada 207 responden yang menyatakan PUAS atau SANGAT PUAS. Sementara yang paling rendah adalah No. 4 (Sarana sosialisasi cukup memadai (LCD, koneksi internet, dll), sebesar $47,9 \%$. 
Tabel 1. Jumlah Responden Yang Merasa Puas Terhadap Sosialisasi

\begin{tabular}{clcc}
\hline Kode & \multicolumn{1}{c}{ Aspek Penilaian } & $\begin{array}{c}\text { Jumlah } \\
\text { Pemustaka } \\
\text { Puas }\end{array}$ & $\begin{array}{c}\text { Prosentase } \\
\text { Pemustaka } \\
\text { Puas }\end{array}$ \\
\hline $\mathbf{1}$ & $\begin{array}{l}\text { Informasi yang disampaikan cukup } \\
\text { memadai }\end{array}$ & 207 & $73,4 \%$ \\
\hline $\mathbf{2}$ & $\begin{array}{l}\text { Cara menyampaikan menarik dan mudah } \\
\text { dipahami }\end{array}$ & 198 & $70,2 \%$ \\
\hline $\mathbf{3}$ & $\begin{array}{l}\text { Bahan untuk sosialisasi cukup memadai } \\
\text { (slide, fotocopy bahan, dll) }\end{array}$ & 152 & $53,9 \%$ \\
\hline $\mathbf{4}$ & $\begin{array}{l}\text { Sarana sosialisasi cukup memadai (LCD, } \\
\text { koneksi internet, dll) }\end{array}$ & 135 & $47,9 \%$ \\
\hline
\end{tabular}

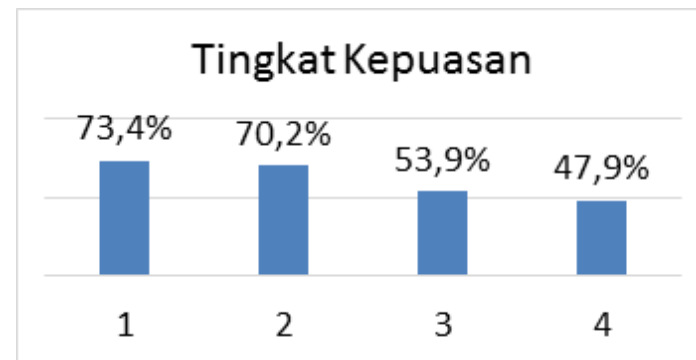

Gambar 2. Jumlah pemustaka puas terhadap acara sosialisasi

\section{Analisis Tingkat Kepentingan/Harapan}

Berdasarkan Tabel. 2, dapat dilihat bahwa tingkat kepentingan/ harapan memiliki nilai tertinggi sebesar 4,49 untuk atribut No. 2 yaitu "Cara menyampaikan menarik dan mudah dipahami", dan memiliki tingkat kepentingan terendah sebesar 4,21 untuk atribut no. 4 yaitu "Sarana sosialisasi cukup memadai (LCD, koneksi internet, dll)."

Secara umum, responden mengangap semua atribut penting untuk pelayanan dengan rata-rata 4,35. Nilai-niai tertinggi dari atribut tersebut dianggap oleh responden sebagai atribut yang sangat penting untuk kegiatan sosialisasi. 
Tabel 2. Rata-rata Tingkat Harapan Terhadap Kegiatan Sosialisasi

\begin{tabular}{clc}
\hline Kode & \multicolumn{1}{c}{ Hal yang dinilai } & $\begin{array}{c}\text { Rata-rata } \\
\text { Harapan }\end{array}$ \\
\hline $\mathbf{1}$ & Informasi yang disampaikan cukup memadai & 4,44 \\
\hline $\mathbf{2}$ & Cara menyampaikan menarik dan mudah dipahami & 4,49 \\
\hline $\mathbf{3}$ & $\begin{array}{l}\text { Bahan untuk sosialisasi cukup memadai (slide, fotocopy } \\
\text { bahan, dll) }\end{array}$ & 4,25 \\
\hline $\mathbf{4}$ & $\begin{array}{l}\text { Sarana sosialisasi cukup memadai (LCD, koneksi internet, } \\
\text { dll) }\end{array}$ & 4,21 \\
\hline & Rata-rata & $\mathbf{4 . 3 5}$ \\
\hline
\end{tabular}

\section{Analisis Tingkat Kinerja/Kepuasan}

Berdasarkan Tabel 3 dapat dilihat bahwa tingkat kepuasan/kinerja memiliki nilai rata-rata tertinggi sebesar 3,8 untuk atribut no.1 (Informasi yang disampaikan cukup memadai) dan no. 2 (Cara menyampaikan menarik dan mudah dipahami), dan memiliki tingkat kepuasan/kinerja terendah sebesar 3,43 untuk atribut no. 4 yaitu "Sarana sosialisasi cukup memadai (LCD, koneksi internet, dll)".

Tabel 3. Rata-rata Tingkat Kepuasan Terhadap Kegiatan Sosialisasi

\begin{tabular}{clc}
\hline Kode & \multicolumn{1}{c}{ Hal yang dinilai } & $\begin{array}{c}\text { Rata-rata } \\
\text { Kepuasan }\end{array}$ \\
\hline $\mathbf{1}$ & Informasi yang disampaikan cukup memadai & 3,80 \\
\hline $\mathbf{2}$ & Cara menyampaikan menarik dan mudah dipahami & 3,80 \\
\hline $\mathbf{3}$ & $\begin{array}{l}\text { Bahan untuk sosialisasi cukup memadai (slide, fotocopy } \\
\text { bahan, dll) }\end{array}$ & 3,53 \\
\hline $\mathbf{4}$ & $\begin{array}{l}\text { Sarana sosialisasi cukup memadai (LCD, koneksi } \\
\text { internet, dll) }\end{array}$ & 3,43 \\
\hline & Rata-rata & $\mathbf{3 . 6 4}$ \\
\hline
\end{tabular}




\section{Analisis Gap dan Radar Diagram Kegiatan sosialisasi Pustakawan}

Analisis ini dilakukan untuk melihat kesenjangan antara kepentingan/ harapan dengan kinerja/kepuasan. Hal ini diperlukan untuk menentukan perioritas perbaikan. Berdasarkan Tabel 4, gap tertinggi antara kepentingan dan kepuasan adalah atribut no. 4 (Sarana sosialisasi cukup memadai (LCD, koneksi internet, dll)), sebesar 0,78. Dan gap terkecil untuk atribut no.1 yaitu "Informasi yang disampaikan cukup memadai ", sebesar 0,64.

Tabel 4. Gap kepuasan dan harapan kegiatan sosialisasilayanan

\begin{tabular}{clccc}
\hline Kode & \multicolumn{1}{c}{ Hal yang dinilai } & $\begin{array}{c}\text { Rata-rata } \\
\text { Kepuasan }\end{array}$ & $\begin{array}{c}\text { Rata-rata } \\
\text { Harapan }\end{array}$ & Gap \\
\hline $\mathbf{1}$ & $\begin{array}{l}\text { Informasi yang disampaikan cukup } \\
\text { memadai }\end{array}$ & 3,80 & 4,44 & 0,64 \\
\hline $\mathbf{2}$ & $\begin{array}{l}\text { Cara menyampaikan menarik dan } \\
\text { mudah dipahami }\end{array}$ & 3,80 & 4,49 & 0,69 \\
\hline $\mathbf{3}$ & $\begin{array}{l}\text { Bahan untuk sosialisasi cukup } \\
\text { memadai (slide, fotocopy bahan, } \\
\text { dll) }\end{array}$ & 3,53 & 4,25 & 0,72 \\
\hline $\mathbf{4}$ & $\begin{array}{l}\text { Sarana sosialisasi cukup memadai } \\
\text { (LCD, koneksi internet, dll) }\end{array}$ & 3,43 & 4,21 & 0,78 \\
\hline \multicolumn{2}{c}{ Rata-rata } & $\mathbf{3 , 6 4}$ & $\mathbf{4 , 3 5}$ & 0,71 \\
\hline
\end{tabular}

Gap tersebut juga dapat dilihat pada gambar radar diagram berikut ini.

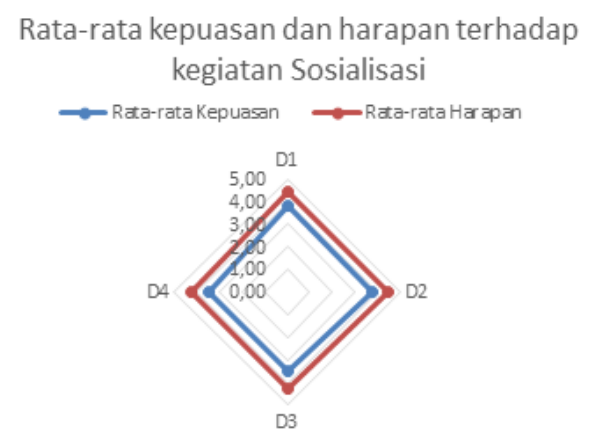

Gambar 3. Radar diagram gap kepuasan dan harapan kegiatan sosialisasi 


\section{Kesimpulan}

Berdasarkan pembahasan pada bab-bab sebelumnya, dapat didimpulkan bahwa mayoritas rrsponden merasa puas atas kegiatan sosialisasi layanan perpustakaan sebesar $61,35 \%$. Yang dianggap puas adalah responden yang memilih PUAS dan SANGAT PUAS. Selain itu, kegiatan sosialisasi berpengaruh positif terhadap tingkat akses pemustakan terhadap layanan perpustakaan.

\section{Ucapan Terimakasih}

Pada kesempatan ini kamu mengucapkan terimakasih kepada Pusat Penelitian dan Penerbitan UIN Sunan Gunung Djati atas bantuan pendanaan dalam riset ini, khususnya untuk Bpk. Dr. Wahyudin Darmalaksana.

\section{Daftar Pustaka}

Akbar, A. K. (t.thn.). http://www.academia.edu. Dipetik 10 5, 2017, dari https://www.academia.edu/6910952/JENIS-JENIS_LAYANAN_DI_ PERPUSTAKAAN?auto=download

Az’mi, Y. U. (2013). Analisis Segitiga Pemasaran Jasa (Pemasaran Internal, Pemasaran Eksternal Dan Pemasaran Interaktif) Di Perpustakaan Universitas Airlangga. Surabaya: Universitas Airlangga.

K, I., \& Octavia, V. (2001). Memanfaatkan Perpustakaan Secara E fektif. Persadha Media Informasi Perpustakaan Universitas Sanata Dharma, 1(1).

K, O. I. (2003). Penerapan Service Quality dalam Usaha Meningkatkan Kualitas Perpustakaan. Persadha Media Informasi Perpustakaan Sanata Dharma, 2(1).

Rangkuti, F. H. (2016). Strategi Pengelolaan Perpustakaan dalam Rangka Meningkatkan Minat Kunjung Siswa di MAN-1 Medan. JIPI (Jurnal Ilmu Perpustakaan dan Informasi), 1(1), 125-137.

Saebani, B. A. (2008). Metode penelitian. Bandung: Pustaka Setia. 
Setiawan, N. (2007). Penentuan Ukuran Sampel Memakai Rumus Slovin Dan Tabel Krejcie-Morgan: Telaah Konsep Dan Aplikasinya. Bandung: UNPAD. Dipetik Oktober 10, 2017, dari www.academia.edu/ download/39080950/penentuan_ukuran_sampel_memakai_rumus_ slovin.pdf

Soeatminah. (1992). Perpustakaan, Kepustakawanan dan Pustakawan. Jakarta: Gramedia Pustaka Utama.

Suwarno, W. (2009). Dasar-dasar Ilmu Perpustakaan: Sebuah Pendekatan Praktis. Yogyakarta: Ar-Ruzz Media.

Yusuf, P. M. (2001). Pengantar Aplikasi Teori Ilmu Sosial Komunikasi untuk Perpustakaan dan Informasi. Bandung: UNPAD. 